\title{
Patterns of drugs prescribed for dental outpatients in Nigeria: findings and implications
}

\author{
Fadare $\mathrm{JO}^{1}$, Oshikoya $\mathrm{KA}^{2}$, Obimakinde $\mathrm{OS}^{3}$, Sijuade $\mathrm{AO}^{1}$, Afolayan $\mathrm{JM}^{4}$, Adeleke $\mathrm{AA}^{3}$, Godman $\mathrm{B}^{5,6,7 *}$, \\ Ojumu $\mathrm{ODO}^{3}$
}

${ }^{1}$ Department of Pharmacology and Therapeutics, College of Medicine, Ekiti State University, Ado-Ekiti. Nigeria. Emails: jofadare@gmail.com; sijuade@hotmail.com

2Department of Pharmacology, College of Medicine, Lagos State University, Lagos, Nigeria. Email: kazeemoshikoya@ymail.com

${ }^{3}$ Department of Dentistry, College of Medicine, Ekiti State University, Ado-Ekiti, Nigeria. Emails:

tasky111@yahoo.com; yinlek@yahoo.com; shikamarujums@gmail.com

${ }^{4}$ Department of Anaesthesia, College of Medicine, Ekiti State University, Ado-Ekiti, Nigeria. Email: jidmic2011@yahoo.com

${ }^{5}$ Department of Laboratory Medicine, Division of Clinical Pharmacology, Karolinska Institutet, Karolinska University Hospital Huddinge, Stockholm, Sweden. Email: Brian.Godman@ki.se

${ }^{6}$ Strathclyde Institute of Pharmacy and Biomedical Sciences, University of Strathclyde, Glasgow, United Kingdom. Email: brian.godman@strath.co.uk

${ }^{7}$ Health Economics Centre, Liverpool University Management School, Liverpool University, Liverpool, UK.

Email: Brian.Godman@liverpool.ac.uk

${ }^{*}$ Author for correspondence: Brian Godman, Strathclyde Institute of Pharmacy and Biomedical Sciences, University of Strathclyde, Glasgow G4 ORE, United Kingdom. Email:

brian.godman@strath.ac.uk. Telephone: 0141548 3825. Fax: 01415522562 and Division of Clinical Pharmacology, Karolinska Institute, Karolinska University Hospital Huddinge, SE-141 86, Stockholm, Sweden. Email: Brian.Godman@ki.se. Telephone + 468 58581068. Fax + 46859581070

Keywords: Antibiotics, Dentistry, Nigeria, Rational Prescribing

(Accepted for publication - Acta Odontologica Scandinavica - Please keep CONFIDENTIAL)

\begin{abstract}
Objectives: There are concerns with inappropriate prescribing of medicines among dentists especially antimicrobials. It is more concerning if this increases resistance rates. This study aimed to address this by assessing patterns of drugs prescribed for outpatients attending hospital dental clinics in Nigeria. The findings used to plan future interventions, particularly around antimicrobial prescribing, where there are concerns. Methods and materials: Medical records of patients attending the dental clinic of a leading teaching hospital in Nigeria were subsequently evaluated. Patients referred for admission, without a prescription, or prescribed medicines without a documented diagnosis were excluded. Results: Overall, 607 prescriptions were analyzed, $314(51.7 \%)$ were for females. Periodontal and gum diseases (414; $68.1 \%)$ was the most frequent diagnosis, followed by pulpitis $(49 ; 8.2 \%)$, and dento-alveolar abscess (43; $7.1 \%) .1798$ medicines were prescribed for all patients with a mean of $3.0 \pm 0.48$ medicines per prescription. Antimicrobials $(1178 ; 65.5 \%)$ and analgesics $(620 ; 34.5 \%)$ were the only drug classes prescribed. Ascorbic acid and vitamin B complex were prescribed for 361(59.5\%) patients. Among antimicrobials, amoxicillin (564; 95.1\%) either alone or combined with clavulanic acid was the most frequently prescribed, followed by metronidazole $(561 ; 94.6 \%)$. Brand name prescribing was also appreciably higher than WHO recommendations. Conclusion: Polypharmacy, brand name prescriptions, and the frequent prescription of antimicrobials were common practices at the dental clinic of this teaching hospital in Nigeria. We suggest a review of the current standard treatment guidelines in Nigeria so as to guide dentists on current knowledge and evidence based treatment of common oral diseases.
\end{abstract}

\section{Introduction}

Prescription audit is necessary in every health care institution as a means of improving the rational use of medicines and subsequently the quality of care for patients [1-3]. Previous prescription audits in Nigeria have identified irrational or inappropriate prescribing [4-6]. The rational use of medicines according to the 
World Health Organization (WHO) is the situation where patients receive medications appropriate to their clinical needs, the doses meet individual patient's requirements, the medicine is used for an adequate period of time, and at the lowest possible cost to them and their community [7]. However, irrational or inappropriate prescribing patterns are common in developing countries [8-11]. Irrational or inappropriate medicine use may be manifested as the prescribing of a medicine when none is indicated; the use of a wrong medicine for a specific condition that requires an appropriate medicine; the use of unproven medicines; the use of a correct medicine but with incorrect administration, dosage, and duration; or the use of unnecessarily expensive medicines when cheaper generics are available [12,13]. Consequently, irrational prescribing can increase the risk of adverse drug reactions as well as other health and economic consequences [13-14].

Many studies on prescribing patterns of dentists, and in dental facilities, have identified inappropriate prescribing of antibiotics as a major problem [11,15-18]. This practice is often a result of non-adherence to available treatment guidelines as seen in India [19], Nigeria [20] and Scotland [21]. Irrational prescribing of antibiotics is known to cause antimicrobial resistance, resulting in therapeutic failure, prolonged hospitalisation and switching to more expensive antibiotics [1, 22-24]. The latter is a concern if patients have to cover the costs of the antibiotics themselves, with the costs of health care already accounting for an appreciable proportion of patients' income in low and middle income countries [25]. Consequently, the extent of inappropriate prescribing of antibiotics by dentists needs to be identified and addressed.

Alongside this, pain is a major symptom in patients with dental problems, which typically necessitates the use of analgesic and anti-inflammatory drugs [26, 27]. According to the WHO [28] and the standard treatment guidelines in Nigeria (STGN) [20], severe, moderate and mild pain should be treated with opioid analgesics, non-steroidal anti-inflammatory drugs (NSAIDs), and paracetamol, respectively. Lack of adherence to the guidelines was responsible for the under-treatment of pain in children with sickle cell anaemia in Nigeria [29]. Consequently, it is necessary to audit how appropriately analgesics are currently being prescribed for dental patients in Nigeria and instigate pertinent interventions to improve management if necessary. Previous audits of outpatient prescriptions in Nigeria have identified vitamins as one of the most over-prescribed medicines [4-6]. However, this was not addressed in previous dental prescription audits since their focus was on antimicrobial and analgesic drugs only [30, 31]. Inclusion of vitamins on the essential medicine list in Nigeria [32], and the lack of caution on its sporadic prescribing in the STGN, might have promoted its irrational prescription [20]. More importantly, the current STGN has inadequately addressed the use of vitamins in common dental diseases, except the supportive use of ascorbic acid in acute necrotizing ulcerative gingivitis [20].

Prescription audits have been conducted in various adult and pediatric medical specialties in Nigeria [4$6,8]$. However, the prescribing habits of dentists in Nigeria have not yet been fully evaluated. Whilst two questionnaire-based studies among Nigerian dental practitioners have investigated the choice of antibiotics, and analgesics usually prescribed, and the rationale behind this [ 30,31 ], a major limitation of these studies is that they did not evaluate the medical records, along with the prescriptions, to determine actual prescribing patterns. This gap in knowledge was the driving factor behind this study. In addition, there is a growing awareness of oral health in Nigeria, which is resulting in increased number of patients visiting public and private dental clinics. As a result, there is an identified need to assess current prescribing against the existing standard treatment guidelines so as to develop evidence-based strategies to address concerns with antimicrobial and analgesic prescribing for pain in dentistry where these exist.

Consequently, in the first instance, this study sought to assess prescribing patterns for patients attending dental clinics in a leading teaching hospital in Nigeria against WHO prescribing indicators [7] and the standard treatment guidelines in Nigeria [20]. Subsequently, use the findings to design pertinent interventions to improve prescribing if needed. We chose a teaching hospital for this initial study because it is affiliated to the Ekiti State University College of Medicine and provides the opportunity for clinical rotations of undergraduate medical and dental students. As a result, any inappropriate prescribing habits learnt during clinical rotations will probably be carried on in practice by newly qualified medical and dental doctors. 


\section{Methods}

\subsection{Study Setting}

This is a cross-sectional retrospective study involving outpatients who attended the dental clinic of the Ekiti State University Teaching Hospital, Ado-Ekiti, South-West Nigeria, between $1^{\text {st }}$ January and $30^{\text {th }}$ June, 2013. The hospital is one of the two tertiary healthcare facilities that provide medical and dental care for the general populace of Ekiti State and other neighboring states. The hospital is well staffed with consultants in various fields including Internal Medicine, Surgery, Pediatrics, Obstetrics and Gynaecology, Psychiatry, Community Medicine, Oral and Maxillofacial Surgery, and Restorative Dentistry. The dental outpatient clinic is also well staffed with dental officers, nurses, dental assistants and technologists.

\subsection{Sampling procedure}

An average of 250 patients (old and new) present every month to the dental outpatient clinic of the hospital. From the daily attendance register, 105 patients were randomly selected per month. The patient record numbers were noted and used to retrieve their case files. Only the case files of patients with documented diagnoses and prescription(s) were selected for the study. Since this study focused entirely on the prescriptions for dental ailments, we excluded those patients with prescriptions only from doctors other than the dentists. We also excluded those with no diagnosis or prescription following dental consultation, and those referred to other specialties such as Ear-Nose-Throat (ENT) and internal medicine. Although we acknowledge exclusion of some dental diseases as a major limitation of the STGN; being the only existing tool guiding medical and dental practice in Nigeria, we assessed adherence of dental prescriptions to the recommendations of the guidelines. The STGN recommends treatments only for acute necrotizing ulcerative gingivitis, acute periapical abscess, alveolar osteitis, cellulitis, dental caries, gingivitis, periodontitis, pericoronitis, oral candidiasis, pulpitis, temporo-mandibular disorders, and salivary gland diseases [20].

\subsection{Data abstraction}

A proforma form, adapted from the forms used in previous drug prescription studies [5,31] was used to abstract information about the demographics of the patients, dental diagnosis made during the visit, and the medications prescribed. The information was abstracted by two dental officers (ODO and AAA) who had been previously trained by the principal investigator (JOF) on how to record the necessary information details. The two dental officers reviewed each case file and the information abstracted to ensure that important details were not missed and to minimize bias. Where there were disagreements on a prescription evaluation, a consultant dental surgeon (OSO) further reviewed the prescription. If the disagreement could not be resolved, the principal investigator intervened and his decision was final. Although we are mindful of the fact that comorbidities may influence dental prescriptions; unfortunately, dental patients with co-existing comorbidities are usually evaluated for comorbidities prior to treatment and their treatment prioritized. Life threatening medical or surgical condition is first treated by referring the patient to the appropriate specialty, and dental treatment is typically provided at a later date when the patient is stable. For patients with stable medical or surgical comorbidities, dental treatments are first rendered before referral to the appropriate specialty. Due to this standard cross-referral between different specialties in the hospital, dental doctors rarely prescribe for coexisting medical conditions in their patients. Consequently, we excluded the prescriptions or current medications for any co-existing medical or surgical co-morbidities.

The medicines prescribed were categorized as prescription drugs or vitamins/ dietary supplements. The prescriptions were assessed according to the WHO drug use indicators. These include the average number of drugs per prescription, percentage of encounters with antibiotics, percentage of encounters with analgesics, and the percentage of drugs prescribed by generic name [33]. Polypharmacy was defined as the prescription of more than one drug other than vitamins/dietary supplements and classified, based on the number of drugs per prescription, as minor (2-3), moderate (4-5), and major $(>5)$ according to the method of Veehof et al [34]. We also assessed the prescription of antimicrobials and analgesics as rational or otherwise using the STGN [20]. 


\subsection{Ethical considerations}

The study protocol was approved by the research ethics committee of the hospital. The patients' data were de-identified and all cases treated anonymously.

\subsection{Statistical analysis}

All data from the medical records were coded and results presented as mean with standard deviation (mean \pm S.D), frequency distribution with percentage, and pictorially. Statistical analysis on the results was performed using the Statistical Package for Social Sciences (SPSS) version 17 software (IBM Corporation, Armonk, NY, USA). Possible association between the gender, age, diagnoses and polypharmacy was explored using Pearson Chi-square test at a significance level of $p<0.05$.

\section{Results}

\subsection{Demographics of the patients}

A total of 630 case files were randomly selected for the study, of which 607 that met the inclusion criteria were included and analyzed in this study. The 23 patients excluded were referred to other specialty clinics because their problems were not primarily dental. Tentative diagnoses made at the dental clinic include pharyngitis (referred to ENT clinic), common cold (referred to family medicine clinic), leukemia manifesting as gum bleeding (referred to Hematology clinic), diabetes manifesting as oral candidiasis (referred to endocrinology clinic), and hemophiliac disease manifesting as gum bleeding (referred to hematology clinic) More females $(314 ; 51.7 \%)$ than males $(293 ; 48.3 \%)$ were recorded in the study. The mean age of the patients was $37 \pm 20.6$ years and the most frequent age group was 21-30 years (Figure 1).

Figure 1: Frequency distribution of the 607 patients with dental disorders according to their age groups

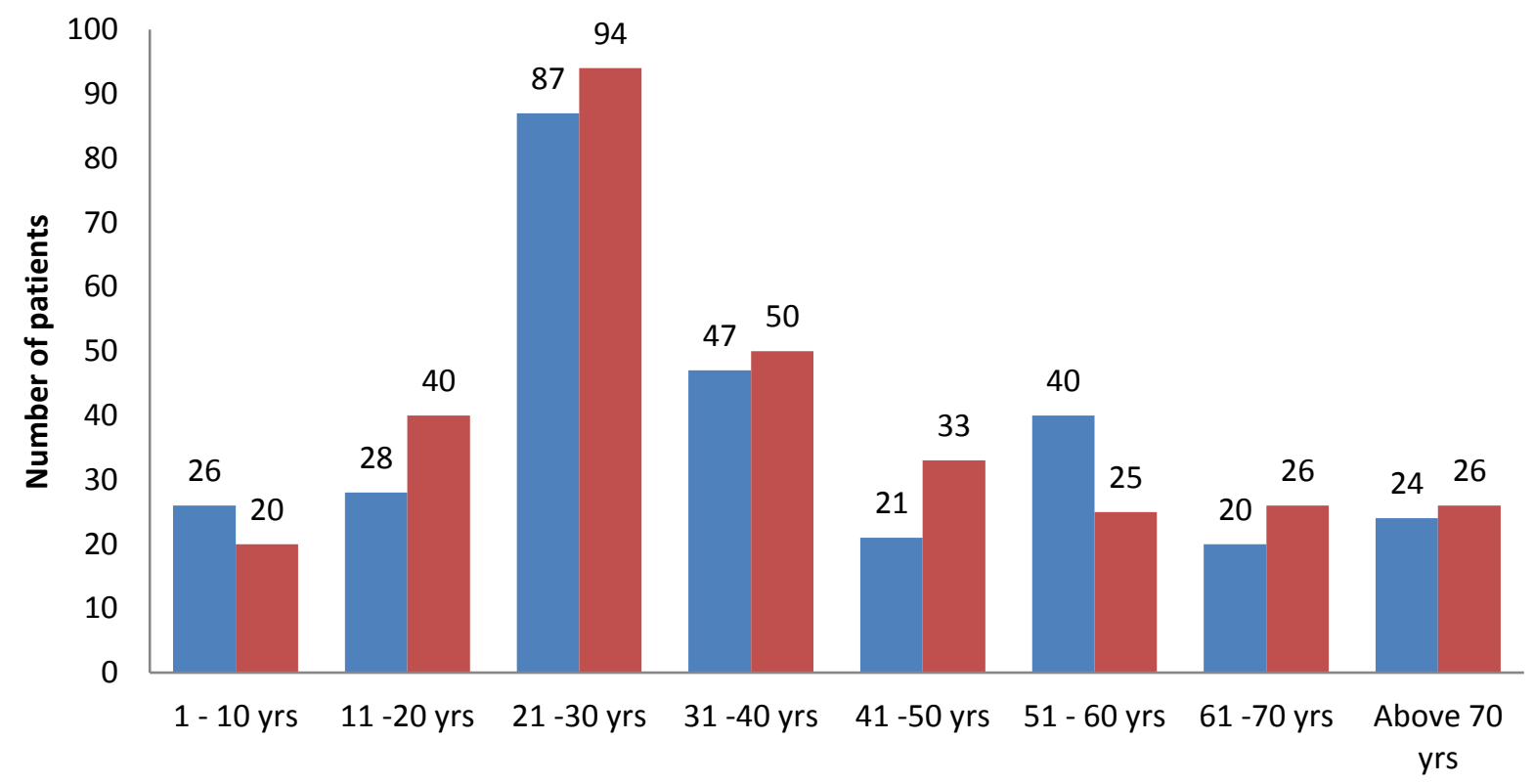

Age group

Male Female 


\subsection{Pattern of dental ailments diagnosed}

The pattern of dental ailments affecting various age groups in this study is presented in table 1.

Periodontal diseases were the most frequently diagnosed and affect all the age-groups in high proportion compared to all other dental ailments reported in this study. Individuals who were 21-30 years old were the most affected with dental ailments. None of the patients had multiple dental ailments. There was a significant association between the dental ailments, age-group and the extent of polypharmacy among the patients $(p<0.001)$.

Table 1: Distribution of dental diagnoses for 607 patients according to their age groups

\begin{tabular}{|c|c|c|c|c|c|c|c|c|c|}
\hline Diagnosis & & & & Ige grou & years) & & & & Total \\
\hline $\begin{array}{l}\text { Included in } \\
\text { the STGN }\end{array}$ & $1-10$ & $11-20$ & $21-30$ & $31-40$ & $41-50$ & $51-60$ & $61-70$ & $>70$ & $\begin{array}{l}\text { of } \\
\text { patients } \\
\text { (\%) }\end{array}$ \\
\hline $\begin{array}{l}\text { Periodontal } \\
\text { disease }\end{array}$ & 10 & 41 & 122 & 71 & 42 & 52 & 35 & 41 & $\begin{array}{c}414 \\
(68.1)\end{array}$ \\
\hline Pulpitis & 8 & 7 & 22 & 5 & 2 & 3 & 2 & 1 & $50(8.2)$ \\
\hline $\begin{array}{l}\text { Dento- } \\
\text { alveolar } \\
\text { abscess }\end{array}$ & 13 & 7 & 11 & 4 & 2 & 2 & 3 & 1 & $43(7.1)$ \\
\hline $\begin{array}{l}\text { Temporo- } \\
\text { mandibular } \\
\text { joint } \\
\text { dysfunction }\end{array}$ & - & 1 & 1 & 2 & 2 & - & 2 & - & $8(1.3)$ \\
\hline $\begin{array}{l}\text { Avulsion } \\
\text { injury to the } \\
\text { lips }\end{array}$ & - & 2 & 2 & - & 2 & - & 1 & - & $7(1.2)$ \\
\hline $\begin{array}{l}\text { Facial } \\
\text { cellulitis }\end{array}$ & 3 & - & - & 1 & - & 1 & - & - & $5(0.8)$ \\
\hline $\begin{array}{l}\text { Buccal space } \\
\text { infection }\end{array}$ & - & 1 & - & - & - & 1 & - & - & $2(0.3)$ \\
\hline $\begin{array}{l}\text { Parotid } \\
\text { papilla }\end{array}$ & - & 1 & 1 & - & - & - & - & - & $2(0.3)$ \\
\hline $\begin{array}{l}\text { Oral } \\
\text { candidiasis } \\
\text { Not included } \\
\text { in the STGN }\end{array}$ & 2 & - & - & 1 & - & 1 & - & - & $4(0.7)$ \\
\hline Retained root & 1 & 3 & 6 & 3 & 1 & 1 & 1 & 2 & $18(3.0)$ \\
\hline $\begin{array}{l}\text { Dentine } \\
\text { Sensitivity }\end{array}$ & 1 & 1 & 2 & 2 & 1 & 2 & - & - & $9(1.4)$ \\
\hline $\begin{array}{l}\text { Peri-apical } \\
\text { cyst }\end{array}$ & 3 & 2 & 1 & 1 & - & - & - & 1 & $8(1.3)$ \\
\hline $\begin{array}{l}\text { Tooth } \\
\text { Fracture }\end{array}$ & 3 & - & - & 2 & 1 & 1 & - & 1 & $8(1.3)$ \\
\hline $\begin{array}{l}\text { Aphthous } \\
\text { ulcers }\end{array}$ & - & 1 & 3 & 2 & - & - & - & 1 & $7(1.2)$ \\
\hline $\begin{array}{l}\text { Fish bone } \\
\text { impaction }\end{array}$ & - & - & 2 & 2 & 1 & - & - & - & $5(0.8)$ \\
\hline
\end{tabular}




\begin{tabular}{|c|c|c|c|c|c|c|c|c|c|}
\hline $\begin{array}{l}\text { Fibro- } \\
\text { epithelial } \\
\text { polyp }\end{array}$ & - & - & 3 & 1 & - & - & - & - & $4(0.7)$ \\
\hline $\begin{array}{l}\text { Impacted } \\
\text { molar }\end{array}$ & - & - & 4 & - & - & - & - & - & $4(0.7)$ \\
\hline $\begin{array}{l}\text { Linguinally } \\
\text { displaced } \\
\text { canines }\end{array}$ & 2 & - & - & - & 1 & 1 & - & - & $4(0.7)$ \\
\hline $\begin{array}{l}\text { Palatally } \\
\text { displaced } \\
\text { canines }\end{array}$ & - & 1 & 2 & - & - & - & - & - & $3(0.5)$ \\
\hline $\begin{array}{l}\text { Lip } \\
\text { angioedema }\end{array}$ & - & - & - & - & - & - & - & 1 & $1(0.2)$ \\
\hline $\begin{array}{l}\text { Kennedy } \\
\text { Class } 4 \\
\text { Edentulous }\end{array}$ & - & - & - & - & - & - & - & 1 & $1(0.2)$ \\
\hline Total & $\begin{array}{c}46 \\
(7.5 \%)\end{array}$ & $\begin{array}{c}68 \\
(11.2 \%)\end{array}$ & $\begin{array}{c}180 \\
(29.7 \%)\end{array}$ & $\begin{array}{c}97 \\
(16.0 \%)\end{array}$ & $\begin{array}{c}55 \\
(9.1 \%)\end{array}$ & $\begin{array}{c}65 \\
(10.7 \%)\end{array}$ & $\begin{array}{c}46 \\
(7.5 \%)\end{array}$ & $\begin{array}{c}50 \\
(8.2 \%)\end{array}$ & $\begin{array}{c}607 \\
(100 \%)\end{array}$ \\
\hline
\end{tabular}

Note: STGN - Standard Treatment Guidelines of Nigeria

\subsection{Pattern of drug prescribing}

\subsubsection{Prescription according to the WHO prescribing indicators}

A total of 1798 drugs were prescribed for all the patients during the study period with a mean of $3.0 \pm 0.48$ drugs per prescription. Antimicrobial agents (1178; 65.5\%) and analgesics $(620 ; 34.5 \%)$ were the two classes of drugs prescribed for the patients. The number of antimicrobial agents and analgesics prescribed for various dental ailments are presented in Tables 2 and 3, respectively. Of the 607 patients studied, antimicrobials were prescribed for 593 (97.7\%); mostly those with periodontal disease (409; $69.0 \%$ ). The remaining 14 patients that were not prescribed antibiotics had tooth fracture (1), linguinally displaced canine (1), oral candidiasis (2), temporomandibular joint dysfunction (2), retained root (3), and periodontal disease (5). Analgesic or anti-inflammatory drugs were, however, prescribed for $596(98.2 \%)$ patients; mostly those with periodontal disease $(410 ; 68.8 \%)$. The remaining 11 patients that were not prescribed analgesics had dento-alveolar abscess (1), dentine sensitivity (1), pulpitis (2), and periodontal disease (6). 
Table 2: Comparing antimicrobial prescription for 593 patients according to oral disorders with current recommendation of the Standard Treatment Guidelines of Nigeria (STGN)

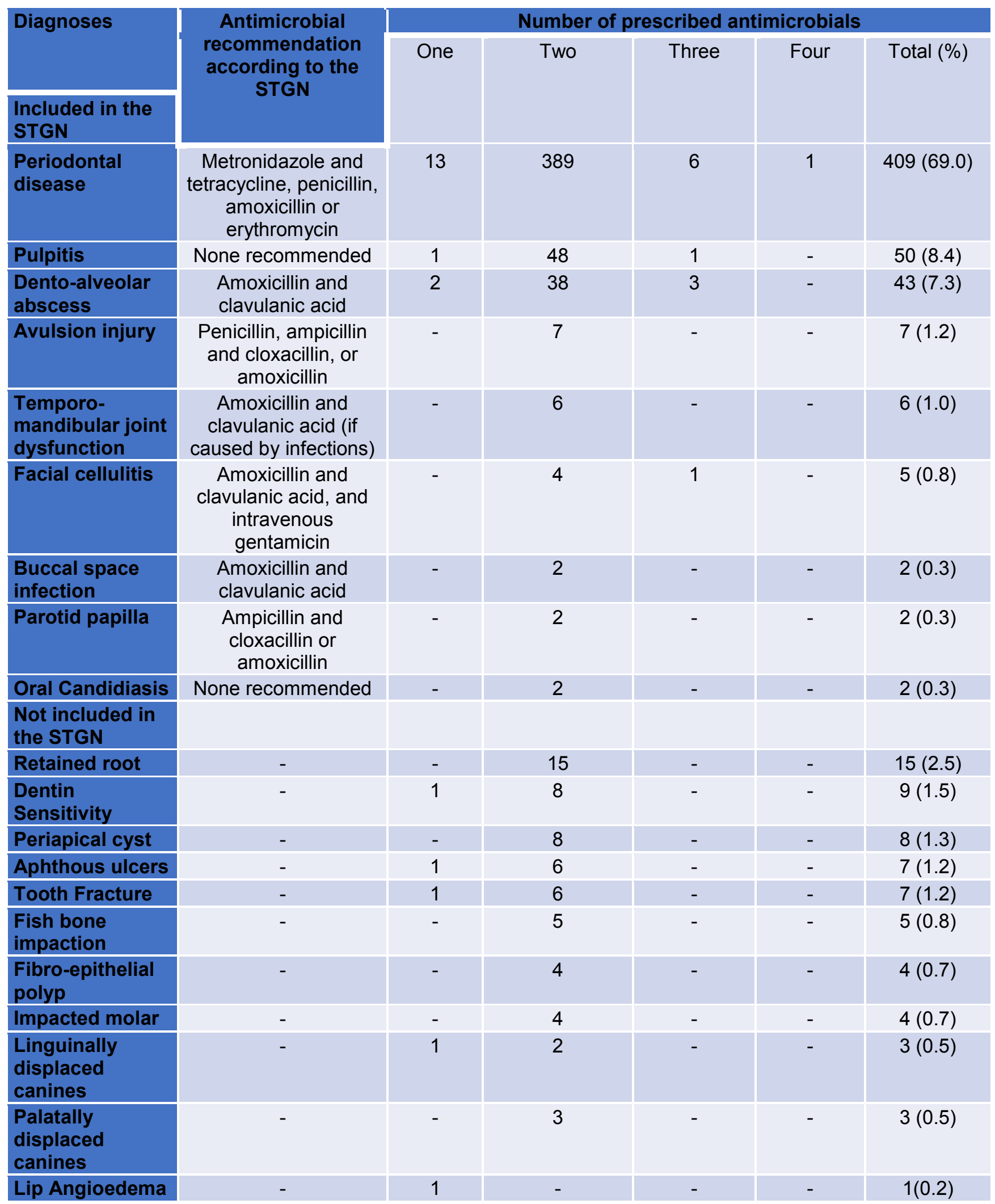




\begin{tabular}{|c|c|c|c|c|}
\hline- & 1 & - & - & $1(0.2)$ \\
\hline $21(3.5 \%)$ & $560(94.4 \%)$ & $11(1.9 \%)$ & $1(0.2 \%)$ & $593(100 \%)$ \\
\hline
\end{tabular}

Table 3: Comparing analgesic prescription for 596 patients according to oral disorders with current recommendation of the Standard Treatment Guidelines of Nigeria (STGN)

\begin{tabular}{|c|c|c|c|c|c|c|}
\hline Diagnoses & Analgesic & & Numbe & f prescl & d anal & \\
\hline & according to the STGN & One & Two & Three & Four & Total (\%) \\
\hline Included in the STGN & & & & & & \\
\hline Periodontal disease & None recommended & 402 & 8 & - & - & $410(68.8)$ \\
\hline Pulpitis & $\begin{array}{l}\text { Paracetamol or non- } \\
\text { steroidal anti- } \\
\text { inflammatory drugs }\end{array}$ & 46 & 2 & - & - & $48(8.1)$ \\
\hline $\begin{array}{l}\text { Dento-alveolar } \\
\text { abscess }\end{array}$ & None recommended & 39 & 2 & - & - & $41(6.9)$ \\
\hline $\begin{array}{l}\text { Temporo- } \\
\text { mandibular joint } \\
\text { dysfunction }\end{array}$ & $\begin{array}{l}\text { Paracetamol or non- } \\
\text { steroidal anti- } \\
\text { inflammatory drugs }\end{array}$ & 7 & 1 & - & - & $8(1.3)$ \\
\hline Avulsion injury & $\begin{array}{l}\text { Paracetamol or non- } \\
\text { steroidal anti- } \\
\text { inflammatory drugs }\end{array}$ & 5 & 1 & - & - & $6(1.0)$ \\
\hline Facial cellulitis & None recommended & 4 & 1 & - & - & $5(0.8)$ \\
\hline Oral Candidiasis & None recommended & 3 & - & - & - & $3(0.5)$ \\
\hline $\begin{array}{l}\text { Buccal space } \\
\text { infection }\end{array}$ & None recommended & 2 & - & - & - & $2(0.3)$ \\
\hline Parotid papilla & $\begin{array}{l}\text { Paracetamol or non- } \\
\text { steroidal anti- } \\
\text { inflammatory drugs (if } \\
\text { requires surgical } \\
\text { procedure) }\end{array}$ & 2 & - & - & - & $2(0.3)$ \\
\hline
\end{tabular}




\begin{tabular}{|c|c|c|c|c|c|}
\hline $\begin{array}{l}\text { Not included in the } \\
\text { STGN }\end{array}$ & & & & & \\
\hline Retained root & 18 & - & - & - & $18(3.0)$ \\
\hline Dentin Sensitivity & 7 & 1 & - & - & $8(1.3)$ \\
\hline Periapical cyst & 7 & - & 1 & - & $8(1.3)$ \\
\hline Tooth Fracture & 8 & - & - & - & $8(1.3)$ \\
\hline Aphthous ulcers & 7 & - & - & - & $7(1.2)$ \\
\hline $\begin{array}{l}\text { Fibro-epithelial } \\
\text { polyp }\end{array}$ & 4 & - & - & - & $4(0.7)$ \\
\hline Impacted molar & 3 & - & 1 & - & $4(0.7)$ \\
\hline Fish bone impaction & 3 & 1 & - & 1 & $4(0.7)$ \\
\hline $\begin{array}{l}\text { Linguinally displaced } \\
\text { canines }\end{array}$ & 4 & - & - & - & $4(0.7)$ \\
\hline $\begin{array}{l}\text { Palatally displaced } \\
\text { canines }\end{array}$ & 3 & - & - & - & $3(0.5)$ \\
\hline Lip Angioedema & 1 & - & - & - & $1(0.2)$ \\
\hline $\begin{array}{l}\text { Kennedy Class } 4 \\
\text { Edentulous }\end{array}$ & 1 & - & - & - & $1(0.2)$ \\
\hline Total & $576(96.6 \%)$ & $17(2.9 \%)$ & $2(0.4 \%)$ & $1(0.1 \%)$ & 596 (100\%) \\
\hline
\end{tabular}

A total of 363 vitamins (both ascorbic acid and vitamin B-complex) was prescribed for 361 (59.5\%) patients (Table 4). Eight hundred and twenty-nine (46.1\%) drugs were generic prescriptions. According to the classification of Veehof et al monotherapy prescription was for periodontal disease (5), retained root (3), tooth fracture (1), and linguinally displaced canine (1). Minor (551; $90.8 \% \%)$ and moderate (45, $7.4 \%$ ) polypharmacy were frequently experienced by the patients. Only one prescription was classified as major polypharmacy. There was a significant association between the dental ailments and the number of drugs prescribed $(p<0.001)$. 
Table 4: The distribution for 361 patients prescribed ascorbic acid according to the dental ailment

$\begin{array}{ll}\text { Diagnoses } & \mathbf{n}(\%) \\ \text { Periodontal disease } & 245(73.4) \\ \text { Pulpitis } & 31(8.6) \\ \text { Dento-alveolar abscess } & 17(4.7) \\ \text { Periapical cyst } & 5(1.4) \\ \text { Retained root } & 15(4.2) \\ \text { Aphthous ulcers } & 5(1.4) \\ \text { Fibro-epithelial polyp } & 4(1.1) \\ \text { Impacted molar } & 1(0.3) \\ \text { Buccal space infection } & 2(0.6) \\ \text { Fish bone impaction } & 3(0.8) \\ \text { Parotid papilla } & 2(0.6) \\ \text { Tooth Fracture } & 5(1.4) \\ \text { Dentin Sensitivity } & 5(1.4) \\ \text { Linguinally displaced canines } & 3(0.8) \\ \text { Avulsion injury } & 5(1.4) \\ \text { Palatally displaced canines } & 2(0.6) \\ \text { Facial cellulitis } & 4(1.1) \\ \text { Temporo-mandibular joint dysfunction } & 5(1.4) \\ \text { Oral Candidiasis } & 1(0.3) \\ \text { Kennedy Class IV Edentulous } & 1(0.3) \\ \text { Total } & 361(100 \%)\end{array}$

Note: Ascorbic acid is not listed in the standard treatment guidelines of Nigeria as part of therapy for any of the dental disorders listed above

The number of drugs per prescription according to different age groups is presented in Figure 2. Monotherapy prescriptions were few and were most received by young patients aged between one and twenty years old. Minor polypharmacy was very common and seen across all age group; experienced most among individuals aged between twenty one and thirty years old. 
Figure 2: The number of medicines prescribed for 607 patients with dental disorders according to their age groups

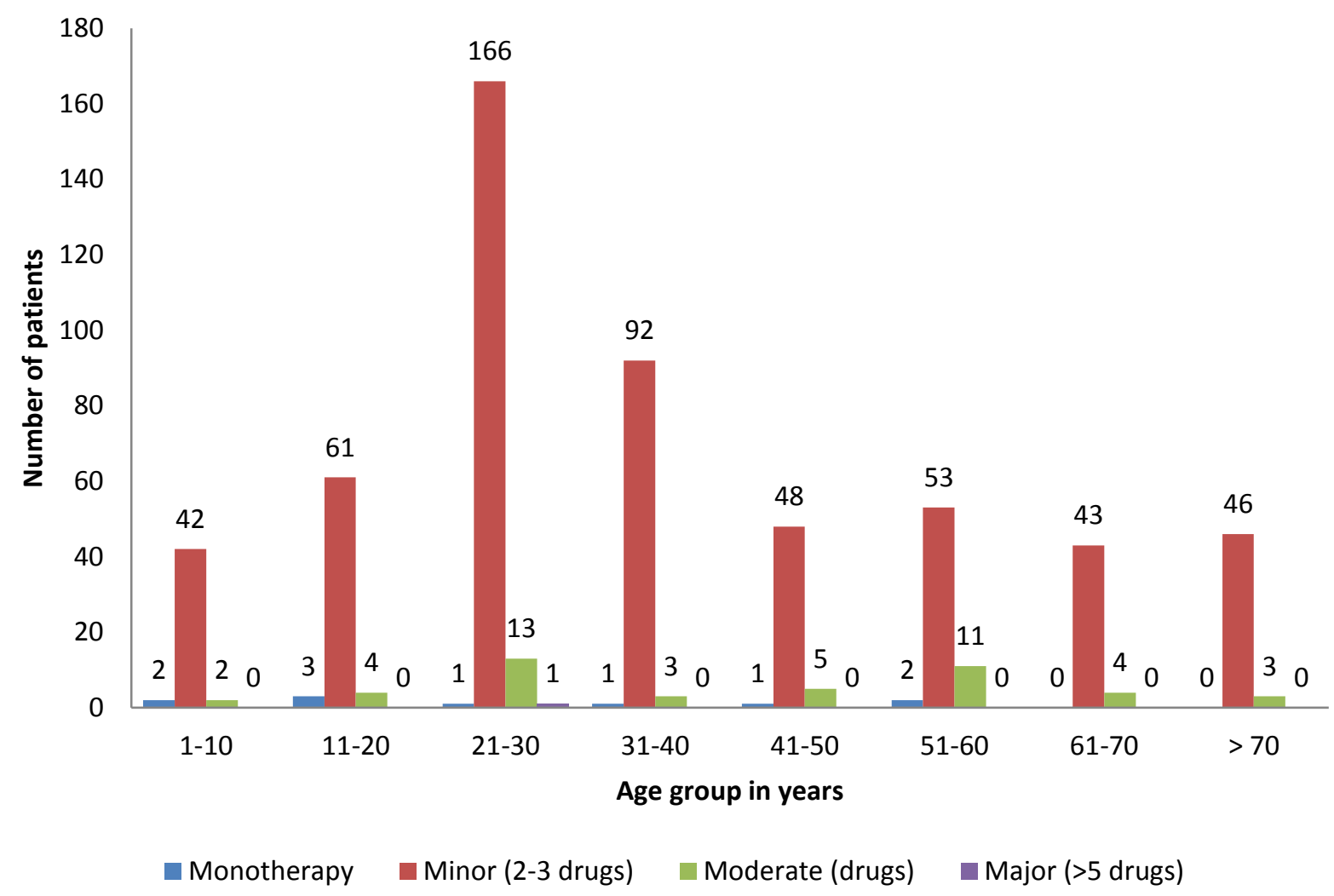

Further analysis of the 593 antimicrobial prescriptions showed only $21(3.5 \%)$ had one antimicrobial, 560 $(94.4 \%)$ had two, $11(1.9 \%)$ had three antimicrobials and one $(0.2 \%)$ had four antimicrobials prescribed. Two antimicrobials, either singly or in combination, were the most prescribed. There was no significant association between the dental ailments and the number of antimicrobials prescribed $(p=0.722)$. The mean number of antimicrobials per prescription was $1.99 \pm 0.31$.

\subsubsection{Rational prescribing}

Antimicrobials were prescribed for practically all the dental ailments reported in this study population (table 2). Of the 414 patients with periodontitis, 409 (98.8\%) received antimicrobials. Similarly, all patients with pulpitis, dento-alveolar abscess, dentine sensitivity and aphthous ulcers received antimicrobials (table 2).

Using the Anatomical Therapeutic Chemical (ATC) classification, the J01C antimicrobials (amoxicillin) were prescribed for most of the patients (564/593; 95.1\%, either alone $(505 ; 89.5 \%$ ) or as a fixed-dose combination with clavulanic acid - 59; $10.5 \%$ ). This was closely followed by the J01XD (metronidazole) prescribed for $561(94.6 \%)$ patients. The combination of amoxicillin alone or amoxicillin-clavulanic acid and metronidazole was prescribed for $550(90.6 \%)$ patients. The distribution of the combined antimicrobial agents is presented in Figure 3. Other antibiotics prescribed were J01A02 (doxycycline) for 26 (4.4\%) patients, J01A07 (tetracycline) for 8 patients, J01FA09 (clarithromycin) for 3 patients, and J01CA01 (ampicillin) for one patient. 
Figure 3: Antimicrobial combination prescribed for 593 patients with common dental disorders

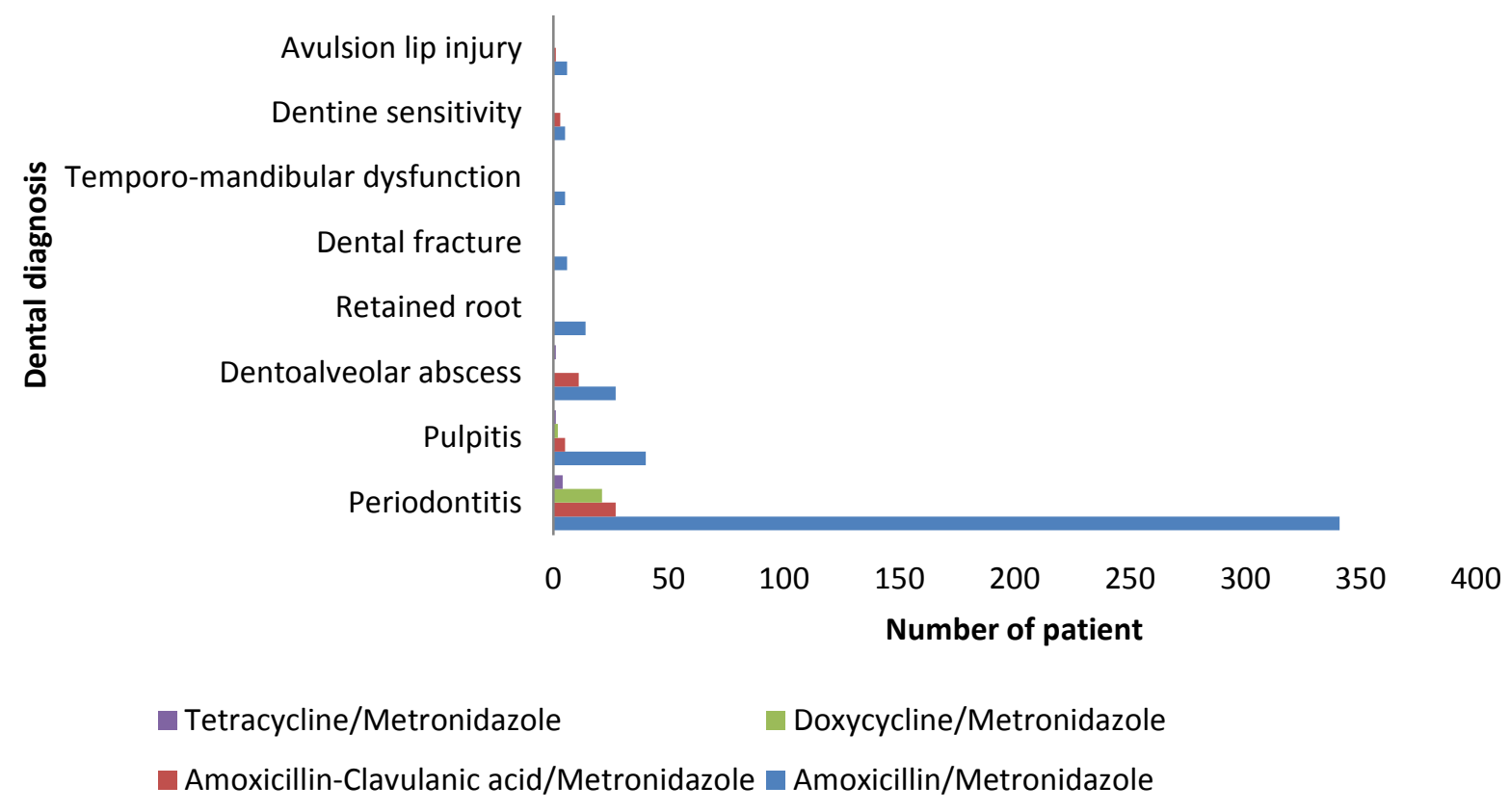

Analysis of the analgesic/anti-inflammatory prescriptions for the 596 patients showed that majority (576; $96.6 \%)$ were prescribed a single analgesic, while $17(2.9 \%)$ were prescribed two types of analgesics (table 3). Only two patients were prescribed three types of analgesics. Using the ATC nomenclature, these were M01AE01 (Ibuprofen - 275; 44.4\%), N02BE01 (Paracetamol - 168; 27.1\%), M01AB05 (Diclofenac - 116; 18.7\%), M01AC06 (Meloxicam - 39; 6.3\%) and N02AX02 (Tramadol - 22; 3.5\%)

\subsubsection{Vitamins and dietary supplement prescribing}

Analysis of the prescribed vitamins showed that they were prescribed for 361 (59.5\%) patients having virtually all the dental ailments (Table 4). Ascorbic acid was the most frequently prescribed vitamin, while vitamin B complex was prescribed along with ascorbic acid for two patients only. However, the prescription was highest for patients with periodontal disease $(245 ; 67.5 \%)$, followed by those with pulpitis (31; 8.5\%) and dento-alveolar abscess (17; 4.7\%).

\section{Discussion}

The majority of the patients presented with periodontal and gum diseases, reflecting the relatively high prevalence of periodontal disease in Nigeria [35] and other developing countries [36, 37]. Individuals in the age group 21- 40 years were the most affected with dental disorders, particularly periodontal disease. This is in keeping with the WHO report that periodontal disease commonly affects the middle-aged (35-44 years) adults and $15-20 \%$ of such cases are often severe [38]. The proportions of male and female patients afflicted with dental disorders were similar in our study. Gender differences have not been explored in detail in dental disorders, but in a few cases, differences have been reported and were attributed to poorer oral hygiene, less positive attitudes toward oral health, and dental-visit behavior among males compared to females [39]. The prevalence (68.2\%) of periodontal disease recorded in our study was higher than the $21.7 \%-29.8 \%$ reported among dental outpatients attending a tertiary dental clinic in southern Nigeria [27] and Pakistan [36]. It was also appreciably higher than the $7.0 \%$ reported among patients attending the dental clinic of a central hospital in Zambia [40]. However, the prevalence was lower than the $96.3 \%$ reported among adolescents and adults attending a dental outpatient clinic in a teaching hospital in northern India [36]. 
Antimicrobial agents and analgesics were the two classes of medicines most prescribed in this study. A similar trend was reported in India [41]. Antimicrobials, analgesics and mouthwashes were also prescribed most in Iran [42] and Jordan [43]. We observed a $65.5 \%$ prescription rate of antimicrobials in this study. This is comparable to the rates reported in Nepal (66\%) [15], but slightly higher than those reported in Iran (54.1\%) [42], Jordan (56.6\%) [43] and Pakistan (53\%) [44]. A much higher prescription rate $(82.1 \%)$ was also reported in dental outpatients in lle-lfe, southwest Nigeria [45].

Over $90 \%$ of the patients were prescribed antimicrobials, and this practice was seen across all the dental ailments. Good dental practices, as indicated by dental treatment guidelines in India [19] and Scotland [21], require a modest use of antimicrobials in dentistry. However, the current STGN could not adequately guide dental prescribing since many important dental disorders were excluded. Of the 21 dental disorders requiring antimicrobial or analgesic, only nine are included in the STGN [20]. This suggests a considerable inadequacy with the current STGN. In line with international practices, the STGN currently recommends a modest use of antimicrobials in periodontal diseases, dento-alveolar abscess, temporomandibular joint dysfunction secondary to infections, facial cellulitis, buccal space infection, and parotid papilla due to infections [20]. It is commendable that patients with these disorders constituted a larger proportion of those prescribed antimicrobials, with the penicillin group of medicines (amoxicillin) being the most prescribed. By contrast, antimicrobials were prescribed for patients with pulpitis and oral candidiasis in spite of not being recommended by the STGN. This suggests some degree of nonadherence to the STGN, which needs to be urgently addressed. Poor adherence to dental prescribing guidelines has been reported as a major cause of antimicrobial over-prescribing in dental practice in the UK. An audit of antimicrobial prescription at two dental practices in the UK showed that $42 \%$ of the 116 prescriptions analysed did not conform to the guidelines of the Scottish Dental Clinical Effectiveness Programme and the National Institute for Health and Clinical Excellence (NICE) guidelines [46].

The deficiencies highlighted in the STGN may well have contributed to the over-prescription of antimicrobials in this study. Such deficiencies include the omission of recommendations for treatment of common dental disorders such as aphthous ulcers. While it may be impossible to include all oral disorders in the STGN, we believe that such common conditions like aphthous ulcers should be included . However, this is not a justification for prescribing antimicrobials when the use is unwarranted. Good dental practice does not support the use of antimicrobials for the 12 dental disorders omitted in the STGN [20]. Approximately $80 \%$ of our patients with retained root and all the four with impacted molars were prescribed antimicrobials during extractions. A South African study that looked at antibiotic-prescribing patterns of dental practitioners following tooth extractions reported approximately $50 \%$ of both healthy and chronically ill patient groups received a prescription contrary to the recommended guidelines [47]. Prophylactic use of antimicrobials during retained-tooth or root extraction is recommended in immunocompromised patients, conditions with evident signs of systemic infection, and a rapidly progressing infection [48]. However, none of these conditions was reported in our patients. Previous studies have shown that prophylactic antimicrobials are often inappropriately prescribed for dental procedures because of oral bleeding [49]. This practice does not conform to international best practice and negates the understanding of the pathophysiological basis for the therapy of dental diseases. Nonetheless, this practice might have influenced the prescribing of antimicrobials for similar procedures in our patients undergoing retained root and impacted tooth extractions. Evidence-based practice does not support oral antimicrobial use for aphthous ulcers [50, 51], dentin sensitivity [52], tooth fracture [53], and periapical cyst [54], yet antimicrobials were prescribed in our study for these situations. We are aware that these conditions could have been infected secondarily and the prescribers might have acted based on this premise. Notwithstanding this, a profound knowledge of the pathogenesis of these conditions, as well as theoretical and evidence-based knowledge of the treatment options, should have guided the practice of the dentists. Topical corticosteroids remain the mainstays of aphthous ulcer treatment [50,51]. Topical tetracyclines may reduce the severity of ulceration and chlorhexidine mouth rinses can reduce the severity and pain of ulceration $[55,56]$. Consequently, the STGN should be revised along the current treatment options for aphthous ulcers

Antimicrobials are also justified in odontogenic infections, non-odontogenic infections such as tuberculosis, syphilis, leprosy and non-specific infections of bone, local infection with signs of fever, and 
prophylactic prevention of infective endocarditis [57]. Most patients with mild periodontal diseases respond very well to conventional therapy (oral hygiene instructions), non-surgical debridement, surgery, and supportive periodontal therapy). Antimicrobial use for periodontal disease is often unnecessary unless it presents with systemic signs of infection or the patient is immunocompromised [58]. Ability to recognize patients with these signs should constitute part of the core dental training in Nigeria. In this study, most of the patients had mild periodontitis, pulpitis or aphthous ulcers which constituted approximately $80 \%$ of those prescribed $2-3$ antimicrobial agents. This practice does not conform to international practice $[19,21]$, and further indicates some form of irrational prescription of antimicrobials amongst dentists in Nigeria. Late presentation of patients with severe forms of their dental ailments is common in Nigeria [59]. Consequently, aggressive treatment of the severe dental ailments may have influenced the over-prescription of antimicrobials observed in our study. There is insufficient evidence to support or refute the benefit of using antimicrobials for control of pain intensity associated with pulpitis [60]. Reliance on alternative information resources such as journal publications, other than the STGN, may have influenced the high prescription rates of antimicrobials for pulpitis in this study. Previous studies from Nigeria, and other lower income countries, have reported the use of multiple information resources for drug information among physicians [61]. However as indicated, irrational use of antimicrobial agents is often associated with adverse events as well as the emergence of new multidrug-resistant bacteria including oral microflora [62,63]; consequently, this should be avoided wherever possible. A review of the current STGN that will cater for some of the identified deficiencies such as aphthous ulcers, and a review of the current state of evidence for the treatment of dental ailments by health authorities and other stakeholders, is recommended. In addition, the introduction of rational prescribing as part of undergraduate and postgraduate curriculum of dentistry should be accorded utmost priority.

Amoxicillin alone or in combination with clavulanic acid was the most commonly prescribed antibiotic, followed by metronidazole. Often, these two classes were prescribed together. This strongly suggests empiric rather than therapeutic use, which deviates from the recommendations of the STGN [20]. The same prescribing patterns have been reported in another study among Nigerian dentists [64] and Ugandan oral healthcare providers [65]. A similar use pattern was also seen in Pakistan [37], India [36], Jordan [43] and Spain [66]. Although antimicrobial prescription for our patients with pulpitis and periodontal disease was not supported by most standard treatment guidelines [19-21], a Nigerian study once reported aerobes as the predominant flora in gingivitis and anaerobes in periodontitis in dental patients [67]. Gram positive, gram negative, anaerobic bacteria, and facultative anaerobes have also been isolated in other dental patients [68-70]. These polybacterial infections might well have informed the penicillin/metronidazole combined prescriptions seen in this study. However, this needs further research before any definitive statements can be made. If antimicrobial agents are inevitable in periodontal diseases, Hancock and Newell suggested that dentists must consider the following when making prescribing choices: what periodontal pathogens are present, susceptibility of the pathogens to the contemplated antibiotics and at what level the antibiotic is delivered into the periodontal pockets [71], reflecting the variations in antibiotic susceptibility to identified periodontal pathogens [72,73]. Treatment based on antibiotic susceptibility as opposed to empirical treatment should result in a significant reduction in the duration of treatment [74].

The most common reason for dental visits in Nigeria [27, 30, 75] and other countries [41-43] is pain, helping to explain the prescribing of analgesics in over $90 \%$ of the patients in this study. The WHO recommends NSAIDs and opioid analgesics for moderate and severe pain, respectively [28]. However, the limited use of opioid analgesics in our study (Figure 3) suggests under treatment of severe pain. In addition, the prescribing of analgesics in the treatment of various dental ailments, except pulpitis, temporomandibular joint dysfunction and parotid papilla, was conspicuously missing in the STGN; a factor that may have contributed to this situation. In some instances, local anesthetic agents, such as lidocaine, were the recommended analgesics in the STGN but are not ready available. The use of instruments for objective pain assessment such as visual analogue scales would assist dental practitioners in pain management. However, this should also be guided by the knowledge of the mode of action of the analgesics; for instance an inflammatory dental condition should be appropriately treated with NSAIDs. In our study, ibuprofen and paracetamol were the most prescribed for pain (Figure 3) similar to the findings from oral surgery clinics in Benin City, Nigeria, and Karachi, Pakistan [76,77]. In Iran, NSAIDs (gelofen and ibuprofen) and paracetamol with- or without-codeine were the most prescribed analgesics [42]. 
Several factors may influence the prescribing of analgesics including pain severity or intended pain, the medical condition of the patient, the type of procedure, the age of the patient, delayed treatment, the economic status of the patient, the uncertainty of diagnosis and patient requests [30]. Overall pain treatment is typically subjective as the severity of the pain and the assessment tool used are typically not documented, as seen in our study. This needs to be addressed given the appreciable number of patients experiencing moderate and severe pain.

Vitamins, especially ascorbic acid, were also prescribed for majority of the patients in our study. This is a significant deviation from the STGN where ascorbic acid was only considered as supportive therapy for acute necrotizing ulcerative gingivitis. Moreover, there is no scientific evidence to support the use of vitamins to prevent or treat oral and dental diseases $[77,78]$. However, in some nutrient deficiency states with oral manifestations, vitamin use is inevitable. . The sporadic prescription observed in this study is, however, concerning because of the potential adverse effects of vitamins in non-deficient states which are well documented $[77,78]$. The STGN should, therefore, emphasize the use of vitamins only in deficient states manifesting as dental disorders.

This study found a high mean number of drugs per prescription (3.0), higher than 1.6 to 1.8 recommended by the WHO [79]. This suggests a problem of over-prescribing, particularly antibiotics. Consequently, increasing the risk of adverse drug-drug interactions and antibiotic resistance as well as adversely affecting compliance and increasing the costs of treatment with high use of brand name prescribing where generic prescribing should not be an issue [1,24, 80-82]. In a study of drug utilization patterns in dental outpatient clinics of tertiary hospitals in Nepal, India and Iran, lower mean numbers of drugs per patient encounter (2.03- 2.64) were reported [15, 41, 42]. Although all the studies, like ours, were conducted in a teaching hospital setting, variation in the mean number of medicines per prescription may be due to differences in the levels of training of the prescribers, non-adherence to standard treatment guidelines and the study population. This study, like those conducted in Nepal and India, involved adolescents and adults, while others have involved children only. This could impact on the comparability of the findings between studies.

The rate of prescribing drugs by generic name (INN - international non-proprietary name) was low (46.1\%), although higher than the $24.5 \%$ reported among dental patients attending a Jordan University Hospital [43] and appreciably higher than none among a teaching hospital in Delhi [83]. This is much lower than the $82.9 \%$ of general dental practitioners prescribing by generic name in Iran [40]. Generic or unbranded drugs are cheaper and save both healthcare providers and patients unnecessarily spending without any deterioration in their care [80, 81, 84]. However, a number of factors are attributed to doctors' failure to prescribe generics. These include economic factors with for example some pharmaceutical companies rewarding doctors who prescribe their products rather than generics as well as physician fears of therapeutic outcomes with generics $[44,81,83]$. The physical appearance or perceived social status of a patient can also be a factor [43].

We acknowledge several limitations including the fact that the study was undertaken in a single setting with potential selection bias as only patients' records with prescribed medications were included in the study. This could affect the interpretation of the overall prevalence of dental conditions and the medicines prescribed. However, typically the majority of encounters between medical practitioners and patients in developing countries end with a prescription. Consequently, we believe that the recorded prevalence in this study may be close to reality. As mentioned earlier, if there are concerns with prescribing practices in this tertiary setting, this is likely to reflect concerns generally throughout Nigeria. It is also likely that the prescribing habits in this teaching hospital will reflect those in other teaching hospitals and secondary healthcare facilities in Nigeria, adding robustness to our findings. We also acknowledge that a prospective study would have allowed dental swabs for culture and antimicrobial sensitivity, enabling greater justification for the antibiotics prescribed. At present, however, such practices are difficult within busy routine dental clinics in Nigerian teaching hospitals as well as dental clinics in the community. Lack of information about the comorbidities in the patients such as HIV infection, tuberculosis and diabetes would require caution in concluding that antimicrobials were over-prescribed, when indeed prophylactic use is highly recommended. Pain assessment with a standardized tool would also have been possible with a prospective study. Despite these limitations, we believe the relative large number of prescriptions 
analyzed and the systematic random selection of patient records used for the study strengthened the robustness of the data generated, providing direction for the future.

\section{Conclusion}

Polypharmacy, brand name prescription, as well as frequent and antimicrobial polytherapy were key identified concerns. This highlights the need for continuing education of dental prescribers on the rational prescribing of medicines, especially antimicrobials, starting in dental school and continuing once qualified.

The STGN currently reflects only a few of the dental disorders reported in this study. Consequently, may not reflect a good source of information for dental prescribing. In view of this, we advocate a comprehensive review of this document, especially the section on the treatment of dental and oral diseases to reflect current state of evidence for good dental practice. More importantly, the STGN needs to be explicit regarding step-by-step management of common dental disorders in Nigeria, highlighting when dental procedures only, pharmacotherapy only, or both is required. Although the management of minor dental conditions such as retained root, dentine sensitivity, peri-apical cyst, tooth fracture, fishbone impaction, fibro-epithelial polyp, impacted molar displaced tooth, lip angioedema, and endetulousness are currently not listed in the STGN, it is important these conditions are included along with emphasis that pharmacotherapy is typically not required; however if necessary, should be guided by the presence of signs of systemic infection such as fever or if the patient is immunocompromised. Good dental practice should be embedded into the practices of trainees and qualified dentists such that, in addition to using the STGN, management of common dental disorders should be guided by their profound knowledge of the pathogenesis of the disease, theoretical and evidence-based treatment options, and knowledge of the drug targets when pharmacotherapy is required. Pending this review, dentists in Nigeria should base their decisions to, and not to, prescribe antimicrobial agents on available evidence in the literature, especially for most dental disorders that were omitted in the current STGN.

Once the STGN has been appropriately updated, encouraging and enforcing the use of STGs for dental conditions in healthcare facilities in the country should also improve the rational use of antibiotics as well as analgesics in the future. This will be the subject of future research.

\section{Acknowledgements}

The authors are grateful to the medical records unit of the dental clinic for their assistance in retrieving the case files and their co-operation throughout the study.

\section{Funding}

This study was self-funded by the investigators. The write up of this paper was in part support by the Karolinska Institutet as well as VR-Link grant from Swedish Research Council (VR-Link 2013-6710).

\section{Conflicts of interest}

The authors declare they have no conflicts of interest.

\section{References}

1. Llor C, Bjerrum L. Antimicrobial resistance: risk associated with antibiotic overuse and initiatives to reduce the problem. Ther Adv Drug Saf. 2014;5(6):229-41

2. Cooper AL, Kazis LE, Dore DD et al. Underreporting high-risk prescribing among Medicare Advantage plans: a cross-sectional analysis. Ann Intern Med. 2013;159(7):456-62

3. Al-Hussein FA. Prescription non-conformities in primary care settings: how useful are guidelines. J Fam Comm Med. 2008;15(2):51-6.

4. Enwere OO, Falade CO, Salako BL. Drug prescribing pattern at the medical outpatient clinic of a tertiary hospital in southwestern Nigeria. Pharmacoepdemiol Drug Saf. 2007;16(11):1244-9

5. Fadare $\mathrm{J}$, Olatunya $\mathrm{O}$, Oluwayemi $\mathrm{O}$ et al. Drug prescribing pattern for under-fives in a paediatric clinic in South-Western Nigeria. Ethiop J Health Sci. 2015;25(1):73-8.

6. Oshikoya K, Chukwura $\mathrm{H}$, Ojo O. Evaluation of outpatient paediatric drug prescriptions in a teaching hospital in Nigeria for rational prescribing. Paediatr Perinat Drug Ther. 2006;7(4):183-8. 
7. World Health Organization. Conference of experts on the rational use of drugs, Nairobi: report on the rational use of drugs. Geneva: World Health Organization 1987. Available from:

http://apps.who.int/medicinedocs/en/d/Js17054e/ (Accessed 15 December, 2016).

$8 . \quad$ Oshikoya KA, Ojo OI. Medication errors in paediatric outpatient prescriptions of a teaching hospital in Nigeria. Nig Q J Hosp Med. 2007;17(2):74-8.

9. Opondo C, Ayieko P, Ntoburi S et al. Effect of a multi-faceted quality improvement intervention on inappropriate antibiotic use in children with non-bloody diarrhoea admitted to district hospitals in Kenya. BMC pediatrics. 2011;11:109

10. Amin A, Khan MA, Azam SM et al. Review of prescriber approach towards rational drug practice in hospitalised patients. J Ayub Med Coll Abbottabad 2011; 23(1):19-22.

11. Konde $S$, Jairam LS, Peethambar $P$ et al. Antibiotic overusage and resistance: A cross-sectional survey among pediatric dentists. J Indian Soc Pedod Prev Dent. 2016;34(2):145-51

12 Dienera $\mathrm{H}$, Limmrotha $\mathrm{V}$. Medication-overuse headache: a worldwide problem. Lancet Neurol 2004; 3(8): 475-483.

13. Laing RO. Rational drug use: an unsolved problem. Trop Doct. 1990; 20: 101-103

14. le Grand A, Hogerzeil HV, Haaijer-Ruskamp FM. Intervention research in rational use of drugs: a review. Health Policy Plan. 1999;14(2):89-102.

15. Sarkar C, Das B, Baral P. An audit of drug prescribing practices of dentists. Indian J Dent Res. 2004;15(2):58-61.

16. Skucaite N, Peciuliene V, Maneliene R et al. Antibiotic prescription for the treatment of endodontic pathology: a survey among Lithuanian dentists. Medicina. 2010;46(12):806-13.

17. Karki AJ, Holyfield G, Thomas D. Dental prescribing in Wales and associated public health issues. Br Dent J. 2011;210(1):E21

18. Dar-Odeh NS, Abu-Hammad OA, Al-Omiri MK et al. Antibiotic prescribing practices by dentists: a review. Ther Clin Risk Manag 2010;6:301-6.

19. Ministry of Health and Family Welfare, Government of India. Standard treatment guideline. Oral health programme: Dental caries and periodontitis. Available at http://clinicalestablishments.nic.in/WriteReadData/475.pdf (Accessed 18 January, 2017).

20. Federal Republic of Nigeria. Standard treatment guidelines, Abuja, Nigeria 2008. (Available at http://www.health.gov.ng/doc/StandardTreatmentGuidelines.pdf (Accessed 18 January, 2017)

21. Scottish Dental Clinical Effectiveness Programme. Drug prescribing for dentistry: dental clinical guidance, second edition. Availabe at

http://www.nhstaysideadtc.scot.nhs.uk/Antibiotic\%20site/pdf\%20docs/Drug Prescribing for Dentistry 2 Web 2[1].pdf (Accessed 16 January, 2017).

22. Ciorba V, Odone A, Veronesi $L$ et al. Antibiotic resistance as a major public health concern: epidemiology and economic impact. Ann Ig. 2015;27(3):562-79

23. Roberts RR, Hota B, Ahmad I et al. Hospital and societal costs of antimicrobial-resistant infections in a Chicago teaching hospital: implications for antibiotic stewardship. Clin Infect Dis. 2009;49(8):1175-84

24. Md Rezal RS, Hassali MA, Alrasheedy AA et al. Physicians' knowledge, perceptions and behaviour towards antibiotic prescribing: a systematic review of the literature. Expert Rev Anti Infect Ther. 2015;13(5):665-80

25. Cameron A, Ewen M, Ross-Degnan D et al. Medicine prices, availability, and affordability in 36 developing and middle-income countries: a secondary analysis. Lancet. 2009;373(9659):240-9

26. Oberoi SS, Hiremath SS, Yashoda R et al. Prevalence of Various Orofacial Pain Symptoms and Their Overall Impact on Quality of Life in a Tertiary Care Hospital in India. J Maxillofac Oral Surg. 2014;13(4):533-8

27. Gbenga Omitola O, Olabisi Arigbede A. Prevalence and Pattern of Pain Presentation among Patients Attending a Tertiary Dental Center in a Southern Region of Nigeria. J Dent Res Dent Clin Dent Prospects. 2010;4(2):42-6

28. World Health Organisation. WHO guidelines on the pharmacological treatment of persistent pain in children with medical illnesses. 2012. Available at:

http://apps.who.int/iris/bitstream/10665/44540/1/9789241548120 Guidelines.pdf (Accessed 12

December, 2016). 
29. Oshikoya KA, Edun B, Oreagba IA. Acute pain management in children with sickle cell anaemia during emergency admission to a teaching hospital in Lagos, Nigeria. S Afr J Child Health 2015; 9(4): 119-123.

30 Azodo CC, Umoh AO. Analgesics prescription in Nigerian dental healthcare services. Nig J Basic Clin Sci. 2013;10(2):86.

31. Azodo CC, Ojehanon PI. Antibiotics prescription in Nigerian dental healthcare services. Odontostomatol Trop. 2014;37(147):34-42

32. Federal Ministry of Health, Nigeria. Essential Medicines list, fifth revision, 2010. Available at http://apps.who.int/medicinedocs/documents/s19018en/s19018en.pdf (Accessed 31 March, 2017).

33. World Health Organization. How to investigate drug use in health facilities: selected drug use indicators. 1993. Available at: http://apps.who.int/medicinedocs/en/d/Js2289e/ (Accessed 20 December, 2016).

34. Veehof L, Stewart R, Haaijer-Ruskamp F, Jong BM. The development of polypharmacy. A longitudinal study. Fam Pract. 2000; 17(3): 261-267.

35. Kubota K, Watanabe H, Hollist NO et al. Dental survey in Nigeria. Part 4. Prevalence and severity of periodontal diseases. Bull Tokyo Med Dent Univ. 1988;35(1-2):11-7.

36. Bansal M, Mittal N, Singh TB. Assessment of the prevalence of periodontal diseases and treatment needs: A hospital-based study. J Indian Soc Periodontol. 2015;19(2):211-5

37. Nazir S, Arain AH, Mohsin A. Prevalence of gingival and periodontal diseases among a teaching hospital patients. J Pak Dent Assoc. 2010;19(4):202-05.

38. World Health Organization. Oral health Fact sheet $N^{\circ} 318$, April 2012. Available at: http://www.who.int/mediacentre/factsheets/fs318/en/ (Accessed 06 June 2017).

39. Reichert S, Stein SA, Gautsch A. Gender differences in HLA phenotype frequencies found in German patients with generalized aggressive periodontitis and chronic periodontitis. Oral Microbiol Immunol 2002; 17: 360-368

40. Kabwe J. The distribution of dental diseases and disorders observed in an urban dental clinic in Zambia. Odonto-Stomatologie Tropicale I. 1996:27-32. Available at: http://www.santetropicale.com/Resume/27404.pdf (Accessed 20 December, 2016).

41. Wadhwa D, Bharti Tomar HG, Bhatia NK et al. Medication Errors in Dentistry-A Cross-Sectional Study. Delhi Psychiatry Jn 2014; 17 (1): 107-112

42. Javad KS, Mahnam B, Sigaroudi FK. Evaluation of Drug Prescription Pattern among General Dental Practitioners in Rasht, Iran. J Dentoaxillofac Rad Path Surg 2012-2013; 1 (2): 18-23.

43. Dar-Odeh N, Ryalat S, Shayyab M et al. Analysis of clinical records of dental patients attending Jordan University Hospital: Documentation of drug prescriptions and local anesthetic injections. Ther Clin Risk Manag. 2008;4(5):1111-7.

44. Tanwir F, Marrone G, Lundborg CS. Knowledge and reported practice of antibiotic prescription by dentists for common oral problems. J Coll Physicians Surg Pak. 2013;23(4):276-81

45. Ogunbodede EO, Fatusi OA, Folayan $\mathrm{MO}$ et al. Retrospective survey of antibiotic prescriptions in dentistry. J Contemp Dent Pract. 2005;6(2):64-71.

46. Kudiyirickal MG, Hollinshead F. Antimicrobial prescribing practice by dentists: a study from two primary care centres in UK. Minerva Stomatol 2011; 60(10): 495-500

47. Lalloo R, Solanki G, Ramphoma K, Myburgh NG. Antibiotic-prescribing patterns of South African dental practitioners following tooth extractions. J Investig Clin Dent. 2016 (Epub). doi: 10.1111/jicd.12247 48. Dar-Odeh NS, Abu-Hammad OA, Al-Omiri MK, Khraisat AS, Shehabi AA. Antibiotic prescribing practices by dentists: a review. Ther Clin Risk Manag. 2010;6: 301-6.

49. Tong DC, Rothwell BR. Antibiotic prophylaxsis in dentistry. A review and practice recommendation. J Am Dent Assoc 2000; 131: 366-374.

50. Altenburg A, El-Haj N, Micheli C, Puttkammer M, Abdel-Naser MB, Zouboulis CC. The treatment of chronic recurrent oral aphthous ulcers. Dtsch Arztebl Int 2014; 111(40): 665-673.

51. Clark D. How do I manage a patient with aphthous ulcers? J Can Dent Assoc 2013; 79 : d48.

52. Gillam D, Chesters R, Attrill D, Brunton P, Salter M, Strand P, Whelton H, Bartlett D. Dentine hypersensitivity-guidelines for the management of a common oral health problem. Dent Update 2013; 40(7): 514-524

53. Mamoun JS, Napoletano D. Cracked tooth diagnosis and treatment: an alternative paradigm. Eur J Dent 2015; 9(2): 293-303. 
54. Narula H, Ahuja B, Yeluri R, Baliga S, Munshi AK. Conservative non-surgical management of an infected radicular cyst. Contemp Clin Dent 2011; 2(4): 368-371.

55. Burgess JA, Johnson BD, Sommers E. Pharmacological management of recurrent oral mucosal ulceration. Drugs 1990; 39(1): 54-65

56. McBride DR. Management of aphthous ulcers. Am Fam Physician. 2000 Jul 1;62(1):149-54, 160.

57. Ramu C, Padmanabhan TV. Indications of antibiotic prophylaxis in dental practice- review. Asian

Pac J Trop Biomed. 2012; 2(9): 749-54

58. Prakasam A, Elavarasu SS, Natarajan RK. Antibiotics in the management of aggressive periodontitis. J Pharm Bioallied Sci. 2012; 4(Suppl 2):S252-5

59. Chukwumah N, Azodo C, Orikpete E. Analysis of tooth mortality among Nigerian children in a tertiary hospital setting. Ann Med Health Sci Res. 2014; 4(3): 345-9

60. Hoskin E, Veitz-Keenan A. Antibiotics are not useful to reduce pain associated with irreversible pulpitis. Evid Based Dent. 2016; 17(3): 81-82

61. Oshikoya KA, Oreagba I, Adeyemi O. Sources of drug information and their influence on the prescribing behaviour of doctors in a teaching hospital in Ibadan, Nigeria. Pan Afr Med J. 2011; 9: 13.

62. Epstein JB, Chong S, Le ND. A survey of antibiotic use in dentistry. J Am Dent Assoc.

2000;131(11):1600-9.

63. American Dental Association. Combating antibiotic resistance. J Am Dent Assoc.

2004;135(4):484-7.

64. Arigbede AO, Adedigba MA, Adeyemi BF et al. Implications of antibiotics and oral contraceptive interactions: knowledge and practice of dental surgeons. Niger Postgrad Med J. 2008;15(3):179-84.

65. Kamulegeya A, William B, Rwenyonyi CM. Knowledge and Antibiotics Prescription Pattern among Ugandan Oral Health Care Providers: A Cross-sectional Survey. J Dent Res Dent Clin Dent Prospects. 2011;5(2):61-6

66. Segura-Egea JJ, Velasco-Ortega E, Torres-Lagares D et al. Pattern of antibiotic prescription in the management of endodontic infections amongst Spanish oral surgeons. Int Endod J. 2010;43(4):342-

50

67. Egwari LO, Obisesan B, Nwokoye NN. Microbiological status of periodontal diseases in Lagos, Nigeria. West Indian Med J. 2009;58(4):392-7.

68. Siqueira JF Jr, Rocas IN. Microbiology and treatment of acute apical abscesses. Clin Microbiol

Rev. 2013;26(2):255-73

69. Walker C, Karpinia K. Rationale for use of antibiotics in periodontics. J Periodontol. 2002;73(10):1188-96.

70. Feres M. Antibiotics in the treatment of periodontal diseases: microbiological basis and clinical applications. Ann R Australas Coll Dent Surg. 2008;19:37-44.

71. Hancock EB, Newell DH. Antimicrobials in periodontal practice. Dent Clin North Am.

1994;38(4):719-31.

72. Christersson LA, Slots J, Rosling BG et al. Microbiological and clinical effects of surgical

treatment of localized juvenile periodontitis. J Clin Periodontol. 1985;12(6):465-76.

73. Scannapieco FA. Periodontal inflammation: from gingivitis to systemic disease? Compend Contin Educ Dent. 2004;25(7 Suppl 1):16-25.

74. O'Connor BC, Newman HN, Wilson M. Susceptibility and resistance of plaque bacteria to minocycline. J Periodontol. 1990;61(4):228-33

75. Ehigiator, O., Odai, C., Obuekwe, O., \& Azodo, C. (2011). Evaluation of drug prescriptions in oral surgery. Nigerian Hospital Practice,2011; 7(5-6): 77-81.

76. Aslam N, Shoaib MH, Bushra R. Analgesic prescribing in developing countries. Jordan J Pharm Sci. 2010; 3(2):137-44.

77. Touger-Decker R. Vitamin and mineral supplements: what is the dentist to do? J Am Dent Assoc. 2007; 138: 1222-1226.

78. NIH State-of-the-Science Conference Statement on Multivitamin/Mineral Supplements and Chronic Disease Prevention. NIH Consens State Sci Statements. 2006 ;23: 1-30.

79. Isah A, Laing R, Quick J et al. The development of reference values for the WHO health facility core prescribing indicators. West Afri J Pharm Drug Res. 2002;18(1):6-11

80. Veronin M. Should we have concerns with generic versus brand antimicrobial drugs? A review of issues. JPHSR 2011;2:135-50 
81. Fadare JO, Adeoti AO, Desalu OO et al. The prescribing of generic medicines in Nigeria: knowledge, perceptions and attitudes of physicians. Expert Rev Pharmacoecon Outcomes Res. 2016;16(5):639-650

82. Godman B, Fadare J, Kibuule D, Irawati L, Mubita M, Ogunleye et al. Initiatives across countries to reduce antibiotic utilization and resistance patterns; impact and implications. Drug Resistance in Bacteria, Fungi, Malaria, and Cancer - Arora, Sajid, \& Kalia Eds Publisher Springer Nature ISBN 978-3-319-486826. Available at URL: https://purestrathacuk/portal/en/publications/initiatives-across-countries-to-reduceantibiotic-utilization-and-resistance-patterns(bb445446-fd1d-47b3-8f91-def5d9e5e3db)/exporthtml.

83. Rehan HS, Singh C, Tripathi CD et al. Study of drug utilization pattern in dental OPD at tertiary care teaching hospital. Indian J Dent Res. 2001;12(1):51-6

84. Godman B, Baker A, Leporowski A, Morton A, Baumgärtel C, Bochenek T, Fadare J et al. Initiatives to increase the prescribing of low cost generics; the case of Scotland in the international context. Medical Research Archives. 2017;5(3):1-34 